\title{
“LÁ EM CIMA O POVO VIVE MAIS, MAS ELES SÃO MAIS VAGABUNDO": ENTRE O OESTE DO PARANÁ E A AMAZÔNIA LEGAL (1980-2014), OS TEMPOS DO TRABALHO NARRADOS NO RETORNO
}

Jorge Pagliarini Junior ${ }^{2}$

RESUMO: Trata-se, a partir de um estudo de memória, da trajetória de sujeitos envolvidos na migração de retorno da Amazônia legal para o Paraná, entre 1990 a 2014. O texto estrutura-se em dois momentos. No primeiro, o cotejamento das fontes orais amparase na análise da processualidade dos discursos de positivação da migração sulista para a Amazônia Legal, sobretudo da migração baseada no trabalho agrícola. Para tanto, apresentase o conteúdo atual (2014) de sites de municípios do estado do Pará que compunham o itinerário da migração. Analisa-se ainda o conteúdo de reportagens do Jornal Nosso Tempo, publicado no Oeste do estado do Paraná, em meados de 1980, reportagens nas quais se reforça o perfil de trabalhador do migrante paranaense, sem que o jornal deixasse de evidenciar o processo de exclusão do pequeno proprietário regional no contexto da implementação do binômio trigo e soja. No segundo momento, problematiza-se o fato de a estrutura das narrativas orais se pautar na ênfase ao trabalho em detrimento do falar de lazer, algo entendido diante da situação do migrante e de sua narrativa, construída, agora, no retorno.

PALAVRAS-CHAVE: Trabalho. Migração de retorno. Memória. História Oral.

1 MOISÉS. Entrevista cedida ao autor-entrevistador. Corbélia/PR, 11 out. 2014.

2 Professor adjunto do curso de História da Unespar, campus de Campo Murão, PR. 
ABSTRACT: Taking a study of memory as starting point, this paper copes with the trajectory of individuals involved in the migration of return phenomenon from Legal Amazônia towards Paraná, considering the historical period of 1990 and 2014. The text is organized in two parts. In the first one, the comparison of the oral sources is supported by the processuality of the discourses of encouragement and extolling on the southern migration towards Legal Amazônia, principally the migration based on the agricultural labor. In doing so, I present the current contents (2014) of websites from different cities situated in the Pará state and which were part of the migration itinerary. In addition, I analyze the contents of reports taken from the newspaper Jornal Nosso Tempo, which used to be published in the West of Paraná state in the mid-1980s. Such reports reinforce the stereotype of Paraná migrants as hardworking people; however, concomitantly, the mentioned newspaper does not fail to evince the exclusion process of small-farm owners (who were living in that region) due to the wheatsoybean binomial implementation. In the second part of the text, I problematize the fact that the structure of oral narratives is based on the emphasis on work instead of speaking about leisure. This is something one is able to understand facing the situation of the migrants and their narratives, built now in return.

KEYWORDS: Work. Migration of return. Memory. Oral History. 


\section{Migrar para trabalhar}

Da fala do senhor $\mathrm{Hugo}^{3}$, temos indícios de como, no processo aqui estudado, migrar significou migrar para trabalhar, e o falar deste processo significou reafirmar trajetória:

E não tinha, não tinham o conhecimento, a técnica da coisa, se dedicavam numa coisa que não era, não tinha apoio de órgãos oficiais e de instituições como tem aqui, não tinha lá, também técnico também não tinha, daí dava com [...] que resultado poderia sair daquilo? O fracasso mesmo! Voltavam; e daí muita gente não conseguia voltar, porque o recurso tava investido tudo lá. Aqui vendia, vamos supor, 15 alqueires e comprava 150 lá.... ${ }^{4}$

A preocupação do entrevistado em se dizer trabalhador e por meio dessa categoria se situar num fluxo migratório nos permite aproximar as trajetórias de migrantes como ele, morador de Marechal Cândido Rondon-PR, migrado para a cidade de Tucumã/ PA em meados de 1980 e retornado em meados de 1990. Sua trajetória diz respeito ao processo de retorno entre a Amazônia legal e o Paraná no período de 1980 a 2014. Foi pela categoria do trabalho, que relacionamos memória e ressignificações do discurso sobre o trabalho, caminho este necessário para entendermos a pluralidade das narrativas orais, situadas pelas falas de 3 dos 20 entrevistados que participaram de uma pesquisa maior ${ }^{5}$.

Para a fundamentação da análise dos discursos e das suas ressignificações das memórias dos entrevistados, e das fontes utilizadas, quais sejam, sites virtuais e jornais tradicionais, o artigo lança mão de dados de um processo migratório muito

3 Cabe destacar que todos os entrevistados assinaram carta de sessão autorizando a utilização das respectivas entrevistas.

4 HUGO. Entrevista cedida ao autor-entrevistador. Marechal Cândido Rondon/ PR, 27 mar. 2014.

5 Conforme tese de doutoramento defendida pelo autor em 2015, suprimida devido às condições de anonimato. 
recentemente mapeado pelo Instituo Brasileiro de Geografia e Estatística - IBGE enquanto um fluxo de retorno, demarcado entre as duas últimas décadas, bem como do processo de urbanização do estado do Paraná, fenômenos esses buscados nos estudos do Instituto Paranaense de Desenvolvimento Econômico e Social - IPARDES, referentes às décadas de 1970 e 1980; todos os indicativos desses índices são aqui problematizados a partir de bibliografia condizente com o debate sobre migração e memória e com a metodologia da História Oral, isso diante das possiblidades existentes entre a produção e os usos da história de vida e da história temática ${ }^{6}$.

O fluxo de retorno foi compreendido a partir do conhecimento da obra "Estudo e Análises, Informações Demográfica e Socioeconômica Número 1: reflexos sobre os deslocamentos populacionais no Brasil" (OLIVEIRA; OLIVEIRA, 2011), publicada pelo IBGE ${ }^{7}$, de caráter investigativo e descritivo, cujos resultados estão relacionados às revisões teóricas e metodológicas da área da Demografia. Os presentes estudos abrangem, então, leituras e revisões dos índices e dos indicativos de recenseamentos ocorridos a partir de 1970 até os indicativos do recenseamento de 2010, dando ênfase às novas configurações dos deslocamentos

6 Busca-se, portanto, avaliar como discursos, leis e políticas são reapropriados pelos entrevistados a partir de uma interpretação dialogal das entrevistas, aqui voltada à história temática (ALBERTI, 2013).

7 De acordo com o Grupo de Estudos do Território e Mobilidade Espacial da População - Gemob. Aqui lidamos com a questão da representatividade, visto que, segundo o IBGE, em 2009 cerca de 203.600 pessoas estavam na condição de imigrantes no estado do Paraná, ou seja, fixaram moradia no estado e, deles, $23 \%$ eram retornados, num total de 46.828 pessoas. A propósito, não pudemos destacar, desse total de retornados, isto devido à falta de estatísticas, uma estimativa referente ao número de paranaenses que retornaram após terem saído dos estados da Amazônia legal. Em 2004, 26.307 imigrantes residentes na região Norte do país eram sulistas (OLIVEIRA, 2011, p. 36, Tabela 6) e esse número caiu para 13.277 em 2009. (Ibid., Tabela 6). Da mesma forma, não pudemos estabelecer o percentual desse montante que retornou para o Paraná, devido à falta de mais cruzamentos de informações pela referida pesquisa. 
populacionais (de 2001-2010). A revisão proposta envolve desde a análise de estudos clássicos, como as vertentes do Funcionalismo e do Estruturalismo, até as interpretações de estudos contemporâneos voltados às estruturas econômicas, políticas e socioculturais, por exemplo, com as contribuições dos Estudos Neoclássicos e da Nova Economia de Migração, desprendidas do modelo de sociedade fordista, do qual se origina a análise clássica (OLIVEIRA, 2011). As principais mudanças desse período foram sintetizadas da seguinte maneira:

I- a inversão das correntes migratórias entre os Estados de Minas Gerais e do Rio de Janeiro; II- a redução da atratividade migratória exercida pelo Estado de São Paulo; III- o aumento da retenção de população na Região Nordeste; IV- os novos eixos de deslocamento às cidades médias no interior do País; V- o aumento da importância dos movimentos pendulares; VI- o esgotamento da expansão da fronteira agrícola; VII- a migração de retorno do Paraná. (OLIVEIRA, 2011, p. 12).

Os tópicos VI e VII, referentes ao esgotamento da fronteira agrícola (da Amazônia Legal) e a Migração de Retorno ao Paraná, ao longo das décadas de 1990 a 2010, evidenciam que se trata de fenômenos interligados. Trata-se de um processo vivenciado por senhor Hugo e agora por ele sendo narrado. Retomando a sua entrevista, de início trataremos da positivação do trabalho sulista e tal esforço de análise e reflexão dialoga com a discussão em torno do conceito de trabalho apresentado por Harvey (1992), esforço voltado à contextualização de um "mundo do trabalho" "fragmentado" que não mais condiz com leituras unilaterais e totalizantes do cotidiano. O diálogo com a concepção da centralidade do trabalho e sobre como tal centralidade nos aproxima das angústias e investigação do processo de migração, nos remete a avaliar, por exemplo, o significado de um entrevistado se dizer, após o seu retorno, um trabalhador envolvido na transformação do trabalho em outras realidades naturais e culturais. 
Seja ao "levar" o estado do Paraná (progresso) consigo, seja ao transformar o meio ambiente, muitas memórias indicaram na direção de trajetórias de desafios e de conquistas pessoais. Algumas vezes essas memórias deram indicações de conquista material, outras tantas de conquistas afirmadas na possibilidade do sustento a partir do próprio esforço ou, ainda, do ganho cultural resultante do processo migratório; para todos os casos ficou ressalvada a contribuição dada pelo trabalho. Aqui podemos retomar Karl Marx, em "Trabalho Estranhado e Propriedade Privada" (MARX, 2008) e seu destaque para a maneira como, a partir do advento do Estado Nacional, o homem se separa do trabalho necessário à vida, paralelamente com a progressiva valorização do mundo das coisas (sachnwelt) e a desvalorização do mundo dos homens (menschanwelt). Desse posicionamento podemos avaliar quais categorias de trabalho construíram os entrevistados. Por exemplo, para Moisés, paranaense, migrado no início do ano de 1991, junto com seus pais, para a cidade de Tucumã/PA, e retornado em meados daquela mesma década, mais que acumular capital, o trabalho, para ele, significou, antes disto, o orgulho de ser reconhecido fora do seu lugar de origem: "Nós fizemos sucesso, cara!" 8.

Diante da reflexão advinda do reconhecimento da reversão do fluxo da migração para a Amazônia e pautados na centralização/ fragmentação do trabalho percebida em tal período, ocupanos a análise da tensão existente entre a positivação do papel desenvolvido pelos migrantes e a maneira como os entrevistados entendem a sua contribuição em processos de colonização daquela região. Este quadro de abordagem das narrativas analisa as maneiras como os entrevistados se apropriam de tradições e as ressignificações que fazem diante dos costumes (THOMPSON, 1998) $)^{9}$, no nosso caso, tanto os costumes "levados" do Sul, quanto

8 MOISÉS. Entrevista cedida ao autor-entrevistador. Corbélia/PR, 11 out. 2014.

9 Temos, na análise da relação entre "costume, lei e direito comum" (THOMPSON, 1998, p. 86-149), a contribuição da História Social, com mais olhares à história agrária, sobre os ritmos da cobrança da Lei e as 
os "encontrados" no Norte. Pela força da tradição e pelo tatear dos costumes, além do reconhecimento da mudança nos ditames políticos e econômicos, podemos avaliar até que ponto o papel positivado do migrante se aproxima e/ou se sobrepõe ao mérito do Paraná no processo. Esta é uma questão em parte respondida pelo senhor Hugo na entrevista com ele. Para falar da maneira de cultivar o solo, o entrevistado recorreu a uma questão cultural, destacando, assim, as contribuições das migrações ora aqui estudadas, bem como as fissuras de políticas nacionais.

A sua narrativa é construída numa estrutura linear e processual, dotada de informações e críticas políticas, leitura esta que denuncia, em parte, a sua formação e atuação profissional, já tendo ele atuado como professor do Ensino Básico e Superior e, atualmente, jornalista. Ao tratar de um recorte de décadas, destaca as dificuldades culturais somadas à falta de projetos subsidiados pelo Estado nacional aos agricultores, além da especulação financeira intensificada durante os projetos de colonização da Amazônia Legal. Ele próprio se disse surpreendido logo após ter migrado para Novo Repartimento/PA, diante das dificuldades em montar uma empresa de venda de produtos veterinários, principalmente devido à carência de boas rodovias que agilizassem o transporte de mercadorias. Aspectos como a propaganda no Sul, a presença de migrantes de outras regiões, além dos sulistas, seu julgamento quanto às boas intenções

resistências que ela encontrou nos "costumes", ao mesmo tempo em que ela foi reivindicada na defesa do "direito comum", do direito consuetudinário, um quadro apropriado em diferentes ritmos principalmente pelos colonos, pequenos proprietários, posseiros e bucaneiros, ou seja, para os pobres. Antes de se ater ao cercamento a partir da história parlamentar, último ato da relação de tratamento entre terras comunais dentro das categorias capitalistas (Ibid,, p. 131), Thompson se distancia da leitura economicista preocupada com as raízes do empreendedorismo inglês e define o período de embates entre direito comum e lei. Leitura que nos direciona, por exemplo, para a intepretação da interação entre sujeitos e a terra, sujeitos e meios de produção, e, numa última análise, sujeitos e a regulamentação legal - do extrativismo; isto perante a ênfase sobre as resistências desses sujeitos pleiteadas nos costumes e ou nas tradições. 
das iniciativas de colonização, e ainda a desilusão de muitos agricultores, essas foram questões que embasaram a sua apresentação do tema da ocupação de parte da região do Pará:

O que que aconteceu com Tucumã, numa vila ali do lado: ali eles tinham criado um projeto, a Ourilândia, a "Gurita", aquela cidade vizinha a Ourilândia, hoje chama-se Ourilândia do Norte. Mas o que aconteceu, Tucumã, ela foi um projeto modelo, criado pelos engenheiros da Andrade Gutierrez, com o pessoal lá, e com as melhores das intenções de criar um [...] porque ali é o filé mion das terras, terra vermelha, parecida com a nossa aqui, conquanto que eles levaram querendo que o agricultor do Sul dominasse lá e colonizasse. Mas como a coisa às vezes pegava uma área de não sei quantos mil hectares do governo lá, fizeram um acerto, fizeram um contrato que eles iam explorar aquilo lá, e colonizaram, abriram um projeto de minifúndio, de pequenas propriedades, menores, e foram com o pessoal do Sul pra lá.

[...] é como nessa região Oeste aqui do Paraná [refere-se ao município de Marechal Cândido Rondon], e aí, eles reservaram, colocaram na entrada, a partir do momento do início da propriedade deles, colocaram uma guarita, uma cancela, um portão, aí o cidadão chegava lá, e aquilo criou uma febre tão grande que tinha propaganda no Brasil inteiro, principalmente aqui no Sul, criou uma febre tão grande, dessa situação, que, muitas gentes de outros lugares foram pra lá. Aí o cara do Goiás foi, do Maranhão [...] aí eles, chegando lá naquela guarita, diziam: "o que você vai fazer? Ah, eu vou abrir outra panificadora..." diziam: "não vai não", não deixavam entrar, "porque já tem alguém lá dentro com esse ramo"; fizeram uma distribuição, e fizeram a seleção e o cidadão que chegou ali com a carga, de caminhão, não tinha pra onde voltar, descarregou ali mesmo, formou a "Gurita", que eles falam pra Guarita. Depois, quando chegou esse povo, e eu estive junto naquela época, deu Ourilândia do Norte. Hoje você pode ver que é uma cidade extensa, não sei se são 10 ou 12 quilômetros, beirando a rodovia PA [...] Tucumã, que era um distrito de São Feliz do Xingu, quando eu cheguei, já tava com melhores condições do que São 
Felix, o município mãe ficou, em termos de desenvolvimento, de toda a estrutura, não tinha a estrutura que o distrito tinha. E eu sou daquela época que Tucumã se emancipou ${ }^{10}$.

O exemplo de Tucumã apresenta mais da dialética que compunha a memória da migração, no seu relacionar entre ganhos e perdas para a região e para a trajetória familiar dos envolvidos. Nesse sentido, a eficácia da migração foi atribuída ao potencial do migrante e confirmada pela afirmativa de que, em poucos anos, o distrito ultrapassaria o município de são Felix do Xingu em grau de desenvolvimento econômico e social, ocorrendo o mesmo com o lugar onde ficaram os barrados, a "Gurita", atual Ourilândia do Norte, lugar onde estavam aqueles que inicialmente não se enquadraram nos planos da colonização. Ou seja, mesmo o lugar abandonado pelo Estado cresceu em conta do esforço de seus colonizadores, muitos deles, sulistas. No site virtual do município, atrelado às informações sobre o processo de colonização da empresa Andrade Gutierrez (CONSAG), temos um texto com a mesma conotação de progresso apresentada pelo entrevistado. Nesse texto consta:

[...] Sabe-se que na década de 1970 um dos grandes objetivos do governo federal 'foi promover a ocupação de vazios demográficos', e sendo a região norte do país uma região predominantemente de áreas de baixa produção agrícola - a maioria dos produtos hortigranjeiros consumidos na região são oriundos do centro-sul do Brasil -, a instalação de uma colonização de caráter agrícola viria resolver dois problemas cruciais: migração da mão-de-obra e a produção local ${ }^{11}$.

10 HUGO. Entrevista cedida ao autor-entrevistador. Marechal Cândido Rondon/ PR, 27 mar. 2014.

11 TUCUMÃ. Prefeitura de Tucumã. Conheça Tucumã: histórico. Disponível em: $<$ http://www.prefeituradetucuma. pa.gov.br/lnstitucional/>. Acesso em: 22 jun. 2014. 
De antemão chama a atenção à relação construída entre migrantes do Centro-Sul e capacidade para atuar na agricultura, frente ao desafio da conquista do "vazio demográfico". Todavia, o exemplo confirmaria apenas em parte o progresso advindo da migração direcionada pelo governo federal, com o projeto abandonado ou pela empreiteira ou pelo governo federal. O histórico do site retira da empresa responsável a culpa pelo abandono da obra e destaca a continuidade de uma colonização até então pautada na autoridade de um conselho local, composto por moradores, migrantes do Centro-Sul:

Em 1983, os investimentos da Andrade Gutierrez destinados ao Projeto Tucumã começaram a diminuir, contribuindo para a não implantação das Glebas II e III e com isso deixou-se de fazer comercialização de lotes aos colonos interessados. Apesar do preço elevado dos lotes, essa situação causou sérios descotentamentos [sic] entre os colonos que haviam chegado à área e não tiveram acesso ao Projeto. A situação da área do Projeto Tucumã ficou cada vez mais tensa e, em 1985, as terras do Projeto foram invadidas, primeiro na área rural, se estendendo depois às agrovilas. Como a empresa preferiu não resistir a essa onda de invasão, o resultado foi um processo de crescimento populacional provocando uma ocupação de forma desordenada nas terras do Projeto, inviabilizando-o como empreendimento de colonização particular. A partir daí começaram as negociações que culminaram na reversão do Projeto de Colonização Tucumã e suas benfeitorias para a União em 30 de outubro de 1988. Com a saída da empresa do Projeto Tucumã e a pouca participação da prefeitura de São Félix do Xingu na área, a comunidade local elegeu nove representantes para a formação do Conselho de Desenvolvimento Comunitário de Tucumã (Codetuc), que tinha como objetivo ordenar as ocupações urbanas, preservando o planejamento urbanístico, áreas ambientais comuns, serviços públicos essenciais e os bens da União guardados e em uso pelo poder público municipal ${ }^{12}$.

12 TUCUMÃ. Prefeitura de Tucumã. Conheça Tucumã: histórico. Disponivel em: $<\underline{\text { http: } / l}$ www.prefeituradetucuma. pa.gov.br/Institucional/>. Acesso em: 22 jun. 2014. 
Assim, teria o conselho local superado o abandono do governo federal e municipal (São Felix do Xingu). É notório como o texto desse site constrói e reforça, após trinta anos, certa memória da colonização. Mesmo não se tendo a preocupação com a consulta sobre o acesso dos entrevistados aos sites citados, e possivelmente isto não deva ter ocorrido com frequência, resta a percepção de que a narrativa construída por esses veículos de imprensa se responsabiliza em propagar um tipo de leitura muito próximo daquela que estrutura parte das entrevistas, como foi o caso do senhor Hugo e de Moisés. E isso não se deve ao acaso, pois, mais que mera repetição, ela indica uma memória presente no cotidiano desses municípios no recorte que nos leva pelo menos às três últimas décadas.

Podemos destacar o fato da agricultura local ter de se adaptar às outras culturas, senão a da soja, produto cultivado por muitos dos agricultores (colonos) que migraram do Sul para aquela região, conforme destacou senhor Hugo, De acordo com a prefeitura, teria sido preciso aguardar pouco mais de uma década para que os migrantes se reestruturassem diante das diversidades e alcançassem o crescimento regional:

A economia de Tucumã está assentada basicamente no setor primário, especialmente sobre as atividades de agropecuária e extrativas vegetal e mineral. Sabe-se que a prioridade do projeto Tucumã ensejava o desenvolvimento da atividade agropecuária e para tanto recrutou colonos principalmente do sul do país, com vivência na exploração dessa atividade, influenciados pela divulgação que a Colonizadora Andrade Gutierrez (CONSAG) fazia da região. [...] A realidade, contudo, era completamente diferente daquela propalada pela referida empresa de colonização privada, pois as famílias de agricultores que chegavam eram assentados nos lotes sem as condições necessárias e suficientes para tornar a agropecuária um dos sustentáculos da economia daquela região. Esses entraves, provavelmente, foram as causas principais do insucesso do Projeto Tucumã. [...] Entretanto a partir dos anos 2000 , houve uma grande mudança estrutural na cadeia produtiva 
da região que se tornou uma grande produtora de arroz, cacau, café, feijão e milho, também sendo uma grande produtora de leite, aliada a expectativa de pavimentação asfáltica da PA-279, principal estrada de ligação do município com o Brasil ${ }^{13}$.

O conteúdo do site envolve uma seara estruturada na relação entre história e esquecimento, e serve para traçarmos um paralelo entre a evidência da fonte e as narrativas da entrevista trazida até aqui. De certa forma, podemos considerar, no texto descritivo do site, tanto o uso da repetição da positivação da migração sulista, quanto do silenciamento dos supostos problemas "trazidos" com a migração. O mecanismo de comunicação - que se diz oficial - utiliza-se do esquecimento decorrente do trauma advindo dos resultados do descaso com o projeto federal ou mesmo, se quisermos, em relação ao impacto ambiental, para evidenciar o progresso - estruturado na ideia de desenvolvimento da nação. Da mesma forma reforça a atitude positiva dos membros do conselho, entre eles, o Senhor Hugo, e dos demais migrantes que tocaram o município nos seus primeiros anos.

Da mesma forma, a fala de Maico, paraense, filho de família migrante que se dirigiu, no início dos anos de 1980, do Oeste do estado do Paraná para Altamira/PA e retornada na última década, destaca um parecer a respeito dos migrantes sulistas: "É, que nem, quem é acostumado aqui, aqui o pessoal fala quando a gente vinha pra cá e que eu, eu falava: 'Vocês tão indo pro Brasil?"14. O Brasil correspondia ao Sul, pois: "Todo mundo era gaúcho, do Paraná pra baixo todo mundo é gaúcho, ou catarinense mesmo, tudo é gaúcho"15. A analogia foi comum entre as fontes orais produzidas. Esses sujeitos são designados por gaúchos e marcaram o processo de migração ocorrido nas décadas de 1980 e 1990. E, na fala de Maico, fica evidente o exemplo da

13 TUCUMÃ. Prefeitura de Tucumã. Conheça Tucumã: histórico. Disponível em: $<$ http://www.prefeituradetucuma. pa.gov.br/Institucional/>. Acesso em: 22 jun. 2014.

${ }^{14}$ MAICO. Entrevista cedida ao autor-entrevistador. Corbélia/PR, 20 jan. 2014. 15 Idem. 
existência de uma presença de discursos ligados à identidade nacional - uma forma de identidade "imaginada" (ANDERSON, 2008), comum aos migrantes; uma forma de imbricar um chamado nacional com a qualidade do migrante- da sua tradição- para colonizar, algo embasado, sobretudo, na disposição e na qualidade de trabalho técnico trazido. A apresentação do período de colonização na região de Altamira, cidade natal de Maico, pelo discurso nacionalista, configura o histórico do município exposto no site oficial:

Altamira teve origem nas missões dos Jesuítas, na primeira metade do séc. XVIII, quando ainda integrava o gigantesco município de Souzel. Através da excursão do Jesuíta Roque de Hunderfund deu-se o primeiro registro histórico de colonização praticada nesse território, onde foi fundada, às margens do Igarapé dos Panelas, uma missão catequética destinada aos índios que habitavam toda a região.

A floresta densa ocupava toda extensão terrestre. Muitas pedras, verdadeiras rochas, que fechavam os percursos fluviais, foram obstáculos aos navegantes, que tiveram de suportar muitas dificuldades para atingir a colonização.

Com auxílio da mão-de-obra indígena, os freis italianos Capuchinhos conseguiram abrir um pequeno atalho o baixo ao médio Xingu. $\mathrm{O}$ projeto foi acelerado com a adequação do trabalho escravo africano na selva amazônica. Em 1880, época em que houve imigração proveniente de várias partes do mundo, começou o povoamento da região entre os igarapés Ambé e Panelas, que posteriormente fomentaria a criação do Município de Altamira, em 6 de Novembro de 1911, já de acordo com a Lei Estadual $n^{\circ} 1.234$.

Ao longo dos anos, a intensificação do comércio e o progresso econômico traçou (sic) o perfil de uma cidade ativa, que passou a ter agências bancárias, hospitais, aeroporto, correios, além de crescimento demográfico e comercial. Altamira vivenciou a vinda de dois Presidentes da República. O primeiro foi Emílio Garrastazu Médice, que em 1970 deu início a construção da Rodovia Transamazônica. Em junho de 1998, o Presidente Fernando 
Henrique Cardoso e demais parlamentares inauguraram o projeto Tramoeste, que trouxe para o município a energia firme de Tucuruí. O grande ponto de referência geográfica da cidade é a rodovia Transamazônica (BR-230), que corta o seu território pelos dois extremos e liga-o ao resto do Brasil. Aberta em 1970, no governo do Presidente Médice, a rodovia proporcionou um grande fluxo migratório para a região.

A rodovia ainda não foi pavimentada. Com a chegada da energia elétrica de Tucuruí, em junho de 1998, a população agora reivindica junto ao Governo Federal o asfaltamento da rodovia para o desenvolvimento da região ${ }^{16}$.

O texto está implicitamente ligado a uma ideia de progresso e transporta para as demandas do século XX uma linha teleológica no intuito de reafirmar ali o progresso nacional. Diferente das cidades destacadas pelos demais entrevistados da pesquisa (Tucumã, Xinguara, Novo Repartimento, no PA; Sorriso, Sinop e Alta Floresta, no MT; Araguaína no TO etc.), a cidade de Altamira tem uma história secularmente identificada. Conforme destacado, são três os períodos que delimitam a história do município: no século XVII, com os jesuítas; no século XIX, com freis capuchinhos e mão de obra escrava; e, principalmente, o período que demarca o impulso do progresso, referente às políticas dos governos militares na década de 1970, com destaque para a construção da BR 230, a Transamazônica. Nessa delimitação pautada em marcos históricos consagrados pela história oficial, a chegada da energia elétrica, em 1998, simbolizou uma conquista e serve de introdução para a expectativa atual da população: o asfaltamento da rodovia transamazônica. Mesmo nessa história secular, não deixa de ser preponderante, na análise da sua linha do progresso, o significado atribuído às transformações da década de 1970, em que podemos analisar o significado de políticas de âmbito nacional, voltadas à colonização da Amazônia Legal. Vale aqui

16 ALTAMIRA. Prefeitura de Altamira. História. Disponível em: <http://altamira. pa.gov.br/portal/?page id=113>. Acesso em: 22 jun. 2014. 
a análise apresentada há pouco a respeito do esquecimento, inclusive, ao serem omitidas as possíveis mazelas do modelo escravocrata que imperou em determinado período da história representada no texto. $\mathrm{E}$, se quiséssemos, poderíamos pensar esses discursos pelo próprio arcabouço teórico metodológico da Análise do Discurso (AD) ${ }^{17}$.

Os posicionamentos de Hugo e de Maico corroboram o papel do movimento. A preocupação com o discurso nacional voltado ao progresso produz esquecimentos e reifica memórias fortes (CANDAU, 2011). Tanto no caso de um como de outro, pois quando reafirmam o perfil do colonizador sulista, eles o fazem em nome do trabalhador agrícola. E vale ressaltar o fato de que nenhum dos entrevistados citados neste texto migrou para trabalhar diretamente com lavoura, ou seja, não se inseriram na construção de fronteiras agrícolas; da mesma foram, apenas dois dos 19 entrevistados, de toda a pesquisa, lidaram com a agricultura.

\section{Positividade do trabalho sulista versus contexto de tensão}

Uma possível interpretação desta leitura de caráter nacionalista e preocupada com a positivação da tradição do migrante trabalhador sulista nesse processo colonizador pode ser buscada, conforme já enunciado na introdução do texto, ainda, nos discursos midiáticos construídos no início da década de 1980, no Oeste do Paraná, lugar de saída/retorno dos entrevistados.

17 Os discursos recorrem à paráfrase (ORLANDI, 2007). A intensificação linear do progresso ocorrera, nessa lógica descritiva, impulsionada pelas elites colonizadoras implícitas no texto e na ideologia percebida, mas não dita. Quanto à tipologia dos discursos, é possível perceber um discurso autoritário, sem que se dê espaço para a polissemia (Idem, p. 86 e 87). Ocorre, nessa tensão marcada pelo esquecimento, produto da memória, aquilo que a autora denomina por interdiscursivo, de memórias marcadas por relações de sentidos, em que se vinculam discursos a outros discursos e relações de antecipação, movimento em que aquele que produz os discursos, a partir dos devidos lugares sociais, se coloca no lugar do receptor. 
Com esse esforço de análise podemos traçar um recorte capaz de contemplar o processo de migração como um todo, afinal, antes do fluxo de retorno, iniciou-se, na década de 1980, isto para o caso das trajetórias dos entrevistados, e de 1970 no cenário das migrações inter-regionais, a migração de ocupação da Amazônia Legal. Para lermos mais a respeito do contexto do Oeste podemos acompanhar uma reportagem do jornal Nosso Tempo ${ }^{18}$, a qual retrata os planos de colonização da Amazônia Legal e demonstra as disputas agrárias daquele momento:

Cinco anos depois, colonos do Oeste paranaense se preparam para colonizar Aripuanã:

CASCAVEL - Cinco anos depois, a Cotriguaçu - Cooperativa Central Regional/Iguaçu, com sede nesta cidade, está pronta para realizar o assentamento de agricultores sem terra do Oeste do Paraná e de outras regiões em imóvel de sua propriedade no Mato Grosso. A gleba soma 1 milhão de hectares, o equivalente a um estado brasileiro das dimensões territoriais de Sergipe, ou nossa microregião, compreendida pelos 29 municípios do Oeste paranaense. Com a assistência de uma cooperativa que a Cotriguaçu pretende implantar na área, os colonos iniciarão a derrubada da mata desde já se capitalizando com a sua comercialização e cultivarão cacau, milho, arroz, café, feijão, guaraná, abandonando em definitivo o binômio do trigo e soja, que de certa forma foi a causa principal de

18 O periódico nasceu muito em conta da compra do jornal semanário Hoje Foz por políticos ligados à Arena, levando a demissão dos três futuros idealizadores do Nosso Tempo, sendo eles os já mencionados jornalistas Aluízio Palmar, além de João Adelino de Souza e Juvêncio Mazzarollo. A postura de esquerda do jornal Nosso Tempo criticava a Lei de Segurança Nacional, a construção da Hidrelétrica Binacional Itaipu e o governo paraguaio de Alfredo Stroessner. De acordo com os idealizadores do projeto de digitalização do jornal, este meio de comunicação teve força na Mesorregião Oeste do Paraná até meados da década de 1980, momento em que passou a enfrentar maiores dificuldades financeiras, dificuldades relacionadas às pressões políticas que fundamentavam sua ideologia. Ainda de acordo com essas informações, era preocupação das edições a construção de críticas aos governos militares latino-americanos e elaboração de discursos de empenho na redemocratização e abertura política. 
seu empobrecimento aqui. Será uma aventura de onze anos, mas a Cotriguaçu dispõe de um sócio importante: o próprio governo federal. Três empresas foram escolhidas para atuar como consórcio no projeto carreando para lá sua experiência e solidez financeira; são a Indeco, Andrade Gutierrez, e Juruena. Em princípio de maio estas empresas já estarão na área iniciando com a Cotriguaçu a implantação definitiva do projeto. (NOSSO TEMPO, 1983a).

A positivação do trabalho sulista com a agricultura prevalece. Mesmo assim, no entanto, a reportagem indica para um contexto de tensão. Na relação entre a notícia que cabe e a intenção de produção de memórias encontramos a construção de um tipo de memória que se espera de um paranaense, cujo perfil lhe conferiria historicamente o afinco e a capacidade de produzir. Dele se espera o saldo produtivo do cultivo, algo alcançado numa espécie de mistura entre as virtudes e as capacidades de mobilização e ou resistência, representada pela vocação e pela oportunidade. Destaca-se mais especificamente sobre a reportagem, a adoção dos conceitos de colono e de pioneiro para a designação do agricultor. No primeiro caso, a designação colono remete a uma categoria substantiva - trabalhador, e, no segundo, a de pioneiro, uma categoria adjetiva - aquele que chegara primeiro e para isso reuniu na sua experiência as devidas capacidades esperadas. Ambas as categorias carregam uma qualidade a partir da qual se tenta justificar a autoridade dos sujeitos com o trabalho na terra e, portanto, o direito de recebê-las, inclusive ao "sem terra", figura central da reportagem. A importância atribuída à iniciativa não impede na matéria a construção da crítica às instituições e ao Estado, parceiros no projeto empreendedor (a cooperativa Cotriguaçu, as empresas Indeco, a A. Gutierez e a Juruena), responsáveis pela afirmação das condições de trabalho e moradia aos migrantes:

Paralelamente, medidas foram tomadas no sentido de ativar o Núcleo Anel, tendo em vista preparar a Empresa para a obtenção de quatro objetivos essenciais: 1 - Dotar o Núcleo pioneiro das 
condições necessárias para servir como apoio logístico a todo o empreendimento. 2 - Iniciar uma produção agrícola e pecuária visando eliminar no menor espaço de tempo possível a dependência econômica junto à Cooperativa Central. 3 - Formar um campo de demonstração e multiplicação de mudas e sementes próprias para a região. A fim de abastecer as necessidades daqueles colonos que lá se instalarão. 4 - Munir-se da tecnologia necessária às condições especiais e peculiares da Amazônia, com o objetivo de prestar serviços de qualidade a custos menores, a esses mesmos colonos. Mesmo deparando-se com dificuldades crescentes, tais como: um tempo exíguo, locomoção precária, dificuldades de acesso a informações sobre economia regional, equipe extremamente reduzida e, principalmente, operando com recursos escassos e que não tem fonte de renda própria, referidos objetivos foram perseguidos, iniciados e, sem dúvida alguma serão alcançados rapidamente. [...]. (NOSSO TEMPO, 1983a).

De antemão, ressalta-se que a intensificação de projetos de colonização privada se apoiou na conjuntura nacional e na suposta "vocação" do sulista trabalhador, cujo perfil fora buscado mediante o processo de colonização em desenvolvimento. Reforçou-se, então, a noção de que esse colono pouco ou nada tinha de posses, algo evidenciado na reportagem acima de maneira direta pelo fato de a colonização ser destinada aos "sem terra" e a eles caberia se adaptar ao cultivo de outras culturas, senão apenas a do binômio milho e soja. Naqueles lugares para onde seriam levados, contariam os migrantes com a grande extensão de terras e com a garantia da mecanização para o plantio. O emprego de tecnologias, experimentado no estado uma década antes, principalmente a partir do cultivo de milho e soja, uma vez instalado o projeto, seria destinado à produção de culturas típicas daqueles lugares.

Não obstante, não podemos perder de vista o fato de que, ao se apropriar do discurso do trabalho no Oeste do Paraná, o Jornal se insere num posicionamento político que remeteu os editores às críticas ao modelo político e econômico nacional do país. Reafirma-se com essas informações, duas pautas de 
reivindicações dos pequenos proprietários e dos "sem terra" de então, no Paraná, sendo elas: a ausência de terra e a preocupação com o processo de concentração fundiária. As dificuldades ressaltadas são seguidas da certeza de que os migrantes lograrão êxito na tentativa, algo supostamente apoiado no perfil "trabalhador" do migrante.

O mapeamento do processo de colonização da Amazônia Legal, ocorrido entre as décadas de 1960 e 1980 pode ser compreendido mediante o diálogo com bibliografia específica. Martins (1986) retrata as dinâmicas migratórias de sulistas para a Amazônia num processo de formação de fronteiras, marcado, segundo ele, pela fronteira capitalista - apresentada a partir da metáfora da cerca - perante as relações de resistências das práticas camponesas que se perpetuavam havia duas décadas antes da produção de sua escrita ${ }^{19}$. Já com Tavares dos Santos $(1993)^{20}$ conhecemos mais desse processo dividido, na referida

19 Na esteira da contribuição de sua obra, destacamos o papel de empresas e dos colonos do Sul apresentados, por esta interpretação, nas contradições vividas na fronteira, análise que encaminha o leitor para o significado do encontro de sujeitos deslocados e em trânsito no tempo e no espaço, sociologicamente situados, segundo ele, pela ausência (MARTINS, 1986, p. 49).

20 Retomando a clássica divisão de Tavares, ela contribui no sentido da contextualização dos períodos, mas também no estabelecimento de proximidades e distanciamentos entre as frentes apresentadas no conjunto das entrevistas com a análise sociológica e histórica. A primeira frente destacada pelo autor foi atribuída às políticas de Vargas entre os anos de 1930 a 1945; naquele período as migrações internas e a intensificação de construção de núcleos coloniais assumidos pelo Estado nacional nas políticas de povoamento pretenderam integrar novas camadas sociais à vida econômica tendo por foco o brasileiro (SANTOS, 1993, p. 28). Nenhum dos entrevistados buscou nesses acontecimentos simetrias com a sua história. $\mathrm{Na}$ verdade, as histórias e analogias começavam com a história familiar dos seus pais, isto na década de 1960 e 1970. Esse período, que marca uma espécie de primeiro momento das trajetórias dos entrevistados, corresponde ao marco temporal da segunda fase migratória de nosso país, segundo o autor, uma forma de resposta do Estado aos movimentos de resistência camponesa e as manifestações no campo. A carência de terras destinadas à Reforma Agraria não foi associada a esse período pelos entrevistados. 
obra, em fases da colonização inter-regional. Em consonância com o autor, lidamos com a centralidade da colonização agrícola na colonização privada ocorrida em detrimento da reforma agrária ${ }^{21}$ (desde os anos de 1940, mas, sobretudo, a partir da intensificação técnica pós-1964).

A atividade de apresentação das fases - evidentemente anterior ao fluxo de retorno que demarca a construção de nossas entrevistas - ressalta, de antemão, argumentações importantes para a sequência de estudo das narrativas orais. Todos entendiam uma ligação entre sua migração e as migrações anteriores, de cunho agrícola, mas eles pouco referenciaram, desse processo, a relação entre o que seria a colonização e o que seria a reforma agrária. E mais, pouco se remetem ao contexto de reivindicações por terras vividas no Paraná durante as décadas de 1980. Isso se deu menos pela ausência de proximidade com tais conflitos do que pelo fato de as suas narrativas apresentarem o migrante pela capacidade do seu trabalho em detrimento da apresentação de conflitos.

O contexto abordado pode ser ainda revisitado pelas contribuições do IPARDES e dele buscamos, além das características agrárias do Oeste e do Sudoeste do Paraná (aqui não citadas) sobre o fenômeno do êxodo urbano, o significado de colono utilizado no estudo sobre a situação fundiária no Paraná de 1979 (IPARDES, 1983). Nele, o conceito de colono é carregado

21 Nessas condições espaciais marcadas pelas ações do Estado e de suas estratégias de ocupação agrária, destaca-se a construção de uma rede de créditos e de outras formas de subsídios aos migrantes. Numa segunda ordem, mais próxima da análise ideológica, o autor evidencia a tentativa de grupos de constituir hegemonia ao lidar com o sonho do pedaço de terras (SANTOS, 1993, p. 16). Outro fator-chave estudado pelo autor implica a análise do conflito vertical, entre colonos sulistas, os posseiros e a elite local (o colono forte e o colono fraco e/ou colono empobrecido) e ao conflito horizontal - entre os migrantes parceleiros, primeira leva de gaúchos, o colono comprador (momento em que falamos dos paranaenses) e o posseiro (Id., p. 165-173) diante da problematização da opção pelo retorno e o papel simbólico de estigmatização que interfere para essa escolha (Id., p. 111-113; 169-174). 
historicamente do sentido moral e prático - algo próximo daquilo que se esperava naquele mesmo contexto de migração rumo à Amazônia, e da não posse das terras: "[...] trabalhador que não dispõe de terras, exerce seu trabalho com auxilio de membros de sua família, em uma extensão de terras pela qual é responsável perante o proprietário, devendo entregar a esse toda a produção e receber salário e gleba para sua subsistência" (IPARDES, 1983, p. 23). Grande parte dessa definição recebeu um novo significado e então esse significado foi levado junto com as famílias que migraram, sendo defendido nas memórias. Destaca-se, assim, a generalização do conceito de colono nas entrevistas: daquele que não teria terras (segundo a definição do relatório), passa-se para o significado daquele proprietário, que se dedicou ao trabalho com a agropecuária (segundo as entrevistas). Essa generalização serve ainda para que os entrevistados se diferenciassem da ideologia próxima a que fundamenta movimentos, mesmo que vivenciaram indiretamente disputas por terras no período da sua migração. Assim, o silenciamento nas entrevistas sobre os conflitos direciona nossa leitura.

A reportagem a seguir apresentou mais do contexto do Oeste paranaense, momento marcado então por reivindicações em prol de reforma agrária, questões que envolvem ainda reivindicações contra as desapropriações promovidas pela Itaipu no início dos anos de 1980. A reportagem nos serviu ao propósito de conhecermos mais a respeito do imaginário construído em torno da Amazônia, região vista como terra de doenças tropicais, como a doença da malária. A notícia intitulada "3000 lavradores na reunião da MASTRO", destacou:

Cerca de três mil agricultores participaram da 3a. Assembléia [sic] do MASTRO - Movimento dos Agricultores Sem Terra, realizada na semana passada em Medianeira. [...]. Na abertura da reunião o agricultor Arcel Barth, um dos líderes dos sem terra, lembrou que "a terra deve ser para quem nela trabalha e dela precisa para viver" e pediu que todos dessem as mãos no sentido de protestar contra a prisão arbitrária de Juvêncio Fviazzarolto que há 9 meses 
amarga no cárcere por ter lutado em defesa dos oprimidos e dos desapropriados de Itaipu. Houve um culto ecumênico presidido pelo bispo Dom Olívio A. Fazza, os pastores Otto Holler e Guilhermo Lieven além dos padres Valdir Riboldi e Tomás Huges. Dom Olívio disse que "se falta pão é porque tem muito egoísmo e falta de compreensão. Se falta pão, falta terra e com terra o povo produz. Com terra o povo terá condições de ter o pão não somente ao agricultor mas para todos os brasileiros e, porque não dizer, na mesa de irmãos de outros países, que necessitam da nossa produção e da produção dos nossos lavradores sem terra". O pastor Otto Holler, por sua vez, leu um trecho da bíblia lembrando Abraão e acrescentou: "Abraão são todos nós que buscamos a terra prometida, mas a ganância de alguns é que nos prejudica. [...]". (NOSSO TEMPO, 1983b).

O teor do debate pode ser avaliado pelas autoridades presentes, bem como pela sabatina de questionamentos pelos quais passaram naquele encontro:

A representante do Incra, dra. Maria Angela Somero, foi sabatinada por uma infinidade de perguntas dos agricultores e contestada em muitas de suas respostas. Disse ela: "Temos terra para quem quiser sair imediatamente do Paraná; temos terras no sul da Amazônia, lotes com 100 hectares para cada agricultor". Um dos lavradores perguntou: - E quem vai suportar as doenças que existem naquela região, especialmente a malária? A resposta da representante do Incra revoltou os colonos: A malária naquela região é como a gripe aqui. Até hoje não temos casos fatais. Um dos agricultores, que já conhece a região, respondeu: É como gripe para quem nunca pegou malária. É como gripe para quem está em Brasília vivendo em seus confortáveis escritórios assistindo a nossa desgraça e querendo mandar a gente para bem longe de nossa terra. Mais tarde usou da palavra o dr. Wagner D'Angelis, presidente da Comissão de Justiça e Paz do Paraná. Ele teceu considerações sobre a política fundiária brasileira frisando que "querer terra é justo e tem amparo legal 
no Estatuto da Terra de 1.964 que possibilita desapropriações por interesses sociais", e sugeriu que o Incra apresente soluções concretas lembrando em seguida palavras do governador José Richa que disse: "Lugar de paranaense é no Paraná" e que quem deveria mudar era o governo. [...] O documento finaliza: "O MASTRO surgiu para levar o grito daqueles que não têm terra. Os agricultores presentes, mais uma vez confirmaram as reivindicações do movimento: Terra no Paraná. Terra só para quem nela trabalha e dela precisa para viver". (NOSSO TEMPO, 1983b).

A palavra "colono" abarca diferentes acepções e, a depender do contexto em que é apropriada, podem ser ressaltadas algumas delas. $E$ a reportagem aponta para o direito sagrado de acesso e a exigência de terra para o povo. Ou seja, vai além da busca pelo progresso ressaltado inclusive em outras reportagens desse jornal as quais já foram discutidas. Mesmo que não estejamos lidando com um movimento social, outras formas de reivindicação estavam postas naquele momento histórico, inclusive uma defesa daqueles que saíram do Paraná dispondo de capital para investir em terras e que trouxeram, entre suas queixas, as dificuldades que afirmaram ter enfrentado diante dos movimentos sociais daquela região ${ }^{22}$.

${ }^{22}$ Cabe aqui destacar que não investigamos as características das propriedades dos entrevistados. Podemos informar que, dos 19 entrevistados, apenas 5 possuíram propriedades no Estado do Pará e, dentre esses, nenhum se considerou grande proprietário. Um deles adquiriu terras a partir da renda de seu emprego, totalizando uma área suficiente para criação de 300 "cabeças de gado"; dois possuíram uma "fazenda" de pouco mais de 150 hectares, algo entre 2 a 3 módulos fiscais. Outros dois não trabalharam com agricultura, mas adquiriram áreas para concessão da extração da madeira mediante projeto de manejo. O que mais chama atenção neste caso é o fato de cinquenta por cento dos entrevistados se dizerem filhos de pequenos agricultores, mesmo aqueles que não seguiram, seja por opção ou por falta de condições como agricultores. Desses, apenas 2 são proprietários de terras agricultáveis. A esse respeito, ver: Lei Federal $n^{\circ} 4.504 / 1964$ (módulo rural); Lei Federal $n^{\circ}$ 8.629/1993 (módulo fiscal). 


\section{Uma resposta aos que ficaram}

Pautados nesse tipo de análise da realidade agrária regional, percebemos como, nas discussões sobre o Oeste, a categoria de trabalhador se confunde agora com a de colonizador, exatamente no momento quando o colono, o colono pacato, trabalhador honesto e não aquele envolvido em movimentos sociais, também passou a ser lembrado entre os pioneiros, cujo símbolo se personificou na imagem do grande proprietário rural ou dos sócios proprietários de companhias colonizadoras atuantes nas regiões. Essa imagem do pioneirismo acabou sendo ressignificada pelos migrantes, se não para justificar a sua trajetória individual, para apresentar um grupo que o representaria, e que migrara uma ou duas décadas antes. Migrou o colono trabalhador e proprietário, mas não o colono envolvido em disputas fundiárias ${ }^{23}$. Todavia, as narrativas não se restringiram à positivação do sulista.

Uma vez destacado o fato de a narrativa oral evidenciar, a priori, a ressignificação do discurso do progresso e o silenciar sobre dificuldades vividas no Paraná, como da ocorrência de movimentos sociais de luta pela terra, na sequência da análise das narrativas orais temos outra linha de argumentação e dela percebemos como, não obstante o silenciamento de conflitos ocorridos no Paraná antes da migração, algumas leituras fazem sentido apenas se analisadas pela perspectiva do retorno, numa forma de resposta aos que ficaram, esta sim, pautada no questionamento do estilo de vida e de trabalho, leia-se, no Paraná, de antes e de agora. Lidamos aqui com uma perspectiva metodológica e epistemológica pautada no conceito de "memórias

23 Das entrevistas não destacadas em conta da proposta do artigo, outras análises delas apresentam como os entrevistados também lidaram, diferentemente daquilo proposto pelos sites estudados, com críticas atuais ao processo de colonização iniciado nas décadas de 1970 (e de 1980 no caso deles especificamente). Servem de exemplo as críticas aos impactos ambientais. Além disso, do fato de eles terem sido incentivados pelo governa a migrar há duas décadas passadas, isso passa a ser cobrado pelos resultados dessa migração. 
divididas" (PORTELLI, 1998) ${ }^{24}$ em contraposição às memórias dicotômicas, e isso contribui com a problemática, quando avaliamos que as entrevistas não se limitaram à valorização do progresso em detrimento das questões fundiárias e/ou ecológicas. Os sujeitos, em sua maioria, não se colocam unicamente em um desses campos.

A propósito do significado de se dizer portador do progresso levado, vale indagar: No caso da leitura desse processo de migração, diante de todas as suas controvérsias, envolveria essa leitura o entendimento de uma nova forma de trabalhar? E acrescentaríamos mais uma interrogação: No caso dos que migraram para o Norte e puderam vivenciar a diferença entre sua forma de ser e a dos nortistas; conseguiriam atualmente, no retorno, construir, com isso, críticas à postura dos paranaenses que ficaram no Paraná e com os quais hoje lidam na sua reinserção? A resposta é sim.

Se é possível traçar uma linha retrospectiva que conecta os sites de municípios do Pará, atuais (2014), aos artigos do jornal de 1980, produzidos no Oeste do Estado, e deles cotejar o conteúdo das memórias, evidenciando a ressignificação da tradição do trabalho levado pelos migrantes sulistas para a Amazônia Legal, devemos problematizar o fato de que o papel do Estado e o mérito da migração

${ }^{24} \mathrm{O}$ autor apresenta a questão discutida quando apresentou estudo sobre a cidade de Civitella Val de Chiana, na qual ocorrera, em junho de 1944, o massacre de 115 civis italianos mortos em um único dia pelos soldados alemães, em retaliação à morte de dois soldados alemães, pela Resistência italiana. Ao questionar a principal construção teórica e metodológica sobre o estudo desse massacre, até então pautada numa divisão, entre, de um lado, uma memória "oficial" - que comemora o massacre como um episódio da Resistência italiana, ou seja, como exemplo para o nacionalismo italiano e, por outro, uma memória local, comunitária, preservada pelos sobreviventes - a memória do luto e das revoltas contra o posicionamento do Estado, e que atribui a culpa das atrocidades à própria resistência que se deu fora dos muros do povoado, e que provocou a ira dos alemães. Portelli julgou essa divisão enquanto dicotômica e simplista, e destacou, em seu estudo do caso, que toda memória é, ao mesmo tempo, ideológica e subjetiva, restando a necessidade do estudo da multiplicidade de memórias entendidas diante de um estudo processual. 
sulista, sobretudo da agrícola, fora lembrado quando se remetia ao período da colonização, mas quase esquecido/silenciado quando falavam da situação atual. Quando se falou do hoje, falou-se não do outro, do "nortista", mas daqueles que ficaram.

$\mathrm{Na}$ entrevista de senhor Hugo percebemos tanto a ênfase dele nas conquistas pessoais quanto nas decepções: "E quando tive meu nome indicado pra diretor do colégio, esse, foi esta a questão, de ter o apoio da comunidade, um ou outro lá, que tinha o sistema de trabalho diferente" 25 . Na sequência, e ainda em forma de um balanço de sua experiência migratória, destacou: "Por ironia, eu quando eu fui, eu tinha uma casa, uma casa bonita. Vendi, me desfiz dela. Quando eu voltei, fui morar de favor na casa da minha mãe e em frente!"26.

A "nostalgia do retorno" à terra natal, lugar sacralizado na e pela memória, decorre da impossibilidade da volta no tempo, pois se alcança a volta ao espaço natal, mas não ao tempo, e o espaço já é outro. O imigrante só deixa de sê-lo quando não é mais assim denominado e, consequentemente, quando ele próprio assim não mais se denomina, não mais se percebe como tal (SAYAD, 2000, p. 11) ${ }^{27}$. De certa forma é possível concluir: os entrevistados se diziam migrantes e não abandonariam, na situação da gravação das entrevistas, a positivação dos seus pares e deles mesmos no processo estudado. Mesmo assim, no entanto, ao falarem a partir da experiência do retorno, os entrevistados se diferenciam dos que ficaram - e se diferenciam justamente pelo trabalho, tal qual se diferenciaram dos nativos ${ }^{28}$ que os receberam. De todo modo, o

25 HUGO. Entrevista cedida ao autor-entrevistador. Marechal Cândido Rondon/ PR, 27 mar. 2014.

26 Id.

27 O referido estudo (SAYAD, 2000) abordou de maneira mais específica o exemplo da migração (migração e imigração) de argelinos durante e logo após o contexto de guerras pelas independências nos anos de 1950 e 1960, visando com isso compreender a noção do retorno na perspectiva de "[...] uma antropologia total do ato de migrar" (Id.).

28 As palavras nativos, nortistas e sulistas se tratam de categorias "nativas" utilizadas pelos entrevistados. 
trabalho que envolve a migração é sinônimo de sucesso. Em linhas gerais, quando se falou dos "nortistas", todos os entrevistados os apresentaram como sujeitos receptivos e pouco enfatizaram conflitos étnicos e/ou regionais. Essas diferenças regionais, porém, marcaram a maneira com falaram do outro e de si. Quando "os daqui vão pra lá" já demostrariam, com isso, que vão para trabalhar. Os acomodados seriam, inclusive, "os que ficam aqui" e também se conformam com pouco. O comparativo se amplia e não se trata tal qual defendido anteriormente, exclusivamente da diferenciação pela cultura/tradição ou pela etnia, mas pelo esforço e pelo realce, já que ser esforçado significa migrar diante da dificuldade.

\section{Mundos do trabalho e outras considerações}

A cultura "do outro" implicou, por exemplo, uma organização urbana precária, na falta de comprometimento com o emprego, mas, também, uma maneira de viver mais feliz! É aquilo que pudemos ler também nas narrativas, como na de Moisés. Para ele, ser uma pessoa boa não implica ser "trabalhadora", e não ser trabalhador não implica falta de caráter, mas uma opção de vida. Ele também foi outro que procurou se diferenciar dos "nortistas", dos costumes de lá, como percebemos na sua fala a seguir ao destacar a preferência que a sua prestação de serviços mecânicos obtinha dos empresários de Tucumã e de Marabá, ambas cidades do Pará, sendo eles sulistas ou não: "O sucesso foi [...] porque o povo do Sul não adianta, nós, povo do Sul, é o povo mais trabalhador que existe, lá em cima o povo vive mais, mas eles são mais vagabundo! Não é que [...] são pessoas boas"29. Eis a frase que abre nosso texto.

Viver mais poderia aludir à acepção de ser mais feliz. Vive-se mais, não no sentido da contagem do tempo do calendário, mas subjetivamente, aproveitando-se mais a vida com lazer, com festas e, consequentemente, com menos trabalho. Viver mais não deixa

29 MOISÉS. Entrevista cedida ao autor - entrevistador. Corbélia/PR, 11 out. 2014. 
de ser uma resposta aos que ficaram e que pouco valorizam o lazer e a vivência familiar, por se preocuparem demasiadamente, não com o trabalho, mas com a acumulação de capital. E a sua trajetória resumiu-se no alcance do respeito pela qualidade do seu trabalho. Assim, ganhou dinheiro e amigos. Com apenas 21 anos ganhou algum dinheiro e o gastou no Paraná, por lógica, "o lugar onde não se ganha dinheiro como lá"30. Ele não pretende voltar ao Pará, pois o dinheiro não valeria se comparado à vida "boa" que leva hoje. De certa forma, o capital acumulado, não exatamente aquele que almejou quando migrou, e não o esperado pelos que ficaram é o suficiente para ele demonstrar que sua trajetória valera a pena, que ele contribuiu com o Pará e conquistou uma bagagem cultural necessária para criticar, inclusive, os que não migraram. Sem que fosse feita a pergunta sobre se teria válido a pena, enfatizou Moisés, de maneira direta: "Eu, olha, meu futuro nunca foi lá, eu sempre pensava fazer um futuro aqui e ir embora, ah, o Paraná nosso aqui não tem, né?"31. Essa afirmativa correspondeu àquilo que apresentou sobre a sua situação atual:

Posso falar a verdade pra você? Tem gente que vai trabalhando e guardando dinheiro, eu não tô guardando dinheiro, eu tô trabalhando e curtindo minha vida, eu e minha mulher ó [...] dá vontade de ir lá em Cascavel? Nós vamos; vamos na pizzaria, lá? Vamos, porque esse negócio de falar: "Ah, não, eu vou guardar dinheiro que mais tarde [...]". Não, [...] eu não sei meu dia de amanhã, então hoje se tem que trabalhar e aproveitar a vida! ${ }^{32}$

Essa conversa é uma forma de reafirmar a trajetória narrada, de valorizar o mundo do trabalho, de se diferenciar dos de lá e, ainda, de se colocar no retorno. Ao que nos parece, esse "lá", mesmo sendo lembrado pelo trabalho, onde "quase se matou de trabalhar", mas onde se "era bom", pela natureza exuberante, 
pelo clima, pelas muitas amizades, pelo reconhecimento de sua qualidade técnica para trabalhar, etc. não era o lugar de "curtir a vida"; mas talvez não fosse apenas uma questão de lugar, mas de momento, e, nessa lógica, agora, mais velho, com certo capital conquistado, agora deva ser, enfim, o momento de curtir.

Concluindo, é válido enfatizar que, em todas as entrevistas, os sujeitos demonstraram ter consciência da diferença entre eles, pequenos, e os grandes empresários; ou, no caso dos que foram na condição de empregado, perceberam a diferença de classe entre os ganhos que obtiveram e os ganhos de seus patrões, uma diferença que não justifica uma crítica genérica ao empresário migrante, mas ao patrão em específico. Ou seja, no caso de Moisés, ele até chega a criticar o seu antigo patrão, mas não o resultado da colonização. Assim entendemos como os entrevistados falaram dos seus "mundos do trabalho". São mundos do trabalho entendidos entre fluxos - da migração privada controlada pelo Estado nas décadas de 1960 a 1980 e pelo fluxo de retorno da virada do século. São mundos do trabalho do sulista que ora ressignifica, na sua trajetória, o sentido de trabalho conforme se esperava da tradição de um migrante, ora critica o trabalho daqueles que ficaram no Paraná. São mundos em que o trabalho é entendido tanto pela afirmativa da contribuição para o desenvolvimento da Amazônia Legal, via generalização da migração agrícola, quanto pelo admitir do insucesso econômico seguido da valorização da conquista cultural, do conhecer de novos costumes.

\section{Referências}

ALBERTI, Verena. Manual de história oral. 3.ed. Rio de Janeiro: Editora FGV, 2013.

ANDERSON, Benedict. Comunidades imaginadas: reflexões sobre a origem e a difusão do nacionalismo. São Paulo: Companhia das Letras, 2008. 
CANDAU, Jöel. Memória e identidade. São Paulo: Contexto, 2011.

COSTA, Solange G. Territórios e mercado de terras no Baixo Amazonas: expansão da sojicultura e valorização fundiária. VI Encontro Nacional da Anppas. Belém, 2012.

FERREIRA, Marieta M.; AMADO, Janaina (Orgs.). Usos e abusos da história oral. 8. ed. Rio de Janeiro: FGV, 2006.

HARVEY, David. Condição pós-moderna: uma pesquisa sobre as origens da mudança cultural. São Paulo: Loyola, 1992. p. 117-161.

INSTITUTO Paranaense de Desenvolvimento Econômico e Social (IPARDES). Paraná. Nova configuração espacial do Paraná. Curitiba 1983. p. 23. Disponível em: <http://www. ipardes.gov.br/ biblioteca/docs/nova configuracao espacial 07 83.pdf>. Acesso em: 22 jan. 2014.

LEONARDI, Victor. Entre árvores e esquecimentos: história social nos sertões do Brasil. Brasília: Paralelo 15 Editores, 1996.

MARTINS, José de Souza. Não há terras para se plantar neste verão. Petrópolis, RJ: Vozes, 1986.

MARX, Karl. Trabalho estranhado e propriedade privada. In: . Manuscritos econômico-filosóficos. São Paulo: Boitempo, 2008. p. 79-90.

NETO, Regina Beatriz Guimarães. Violência e trabalho na Amazônia: narrativa historiográfica. Revista Territórios \& Fronteiras, Cuiabá, v. 7, n. 1, p. 27-46, abr. 2014. Disponível em: $<$ http://www.ppghis.com/territorios\&fronteiras/index.php/v03n02/ issue/view/ 14/showToc>. Acesso em: 21 jun. 2014.

NOSSO TEMPO (Digital). Cinco anos depois, colonos do Oeste paranaense se preparam para colonizar Aripuanã. Nosso Tempo, 
Foz do Iguaçu, ano II, n. 65, p. 16, 21-28 de abr. 1983a. Disponível em: <http://www.nossotempodigital.com.br/>. Acesso em: 10 mar. 2013.

NOSSO TEMPO (Digital). Queremos terra no Paraná. Nosso Tempo, Foz do Iguaçu, ano II, n. 71. p. 18, 2-8 jun. 1983b. Disponível em: <http://www.nossotempodigital.com.br/>. Acesso em: 10 mar. 2013.

ORLANDI, Eni P. Análise do discurso: princípios e procedimentos. Campinas: Pontes, 2007.

OLIVEIRA, Luiz A. Pinto de; OLIVEIRA, Antônio T. Ribeiro de (Orgs.). Reflexões sobre os deslocamentos populacionais no Brasil. Rio de Janeiro: IBGE, 2011.

PORTELLI, Alessandro. O massacre de Civitella Val di Chiana (Toscana: 29 de junho de 1944): mito, política, luto e senso comum. In: FERREIRA, Marieta M.; AMADO, Janaina (Orgs.). Usos e abusos da história oral. Rio de Janeiro: FGV, 1998.

SANTOS, José Vicente Tavares dos. Matuchos: Exclusão e Luta (Do Sul para a Amazônia Ocidental). Petrópolis: Vozes, 1993.

THOMPSON, Edward P. Costumes em comum. São Paulo: Companhia das Letras, 1998. p. 86-149.

Recebido em abril de 2016. Aprovado em janeiro de 2017. 